\title{
A Note on a New Weighted Idiosyncratic Risk Measure
}

\author{
Yin-Ching $\operatorname{Jan}^{1}$ \\ ${ }^{1}$ Department of Distribution Management, National Chin-Yi University of Technology, Taiwan \\ Correspondence: Yin-Ching Jan, Department of Distribution Management, National Chin-Yi University of \\ Technology, Taiwan. E-mail: jan511@mail.ncut.edu.tw
}

Received: May 15, 2014

Accepted: June 9, 2014

Online Published: June 30, 2014

doi:10.5430/ijfr.v5n3p194

URL: http://dx.doi.org/10.5430/ijfr.v5n3p194

\begin{abstract}
This note remedies a risk measure, which was proposed by the work of Jan and Wang (2012). They used property of martingale to measure idiosyncratic risk, and illustrated that it is better than the measurements of variance and semivariance. However, their risk measure can't distinguish between the assets whose return rising firstly and then declining, and the assets whose return declining firstly and then rising. In this note, I propose a remedied method, which puts more weight to the recent return's variation, and demonstrate that the new weighting risk measure is more close to the investor risk conception.
\end{abstract}

Keywords: risk measure, martingale, idiosyncratic risk

\section{Introduction}

Only systematic risk is priced in the traditional asset pricing model. That is because the idiosyncratic risk can be diversified away and therefore should not play any role in the risk premium. However, Merton (1987) states that idiosyncratic risk should be priced when investors hold undiversified portfolios. When investors don't hold the diversified portfolios, the investors' portfolios retain the idiosyncratic risk. As a result, risk premium should be compensated for the idiosyncratic risk when investors are risk averter.

Many studies have discovered that idiosyncratic risk premium can help to explain expected asset return. See, for example, the studies of Malkiel and Xu's (1997), Malkiel and Xu (2003), Goyal and Santa-Clara (2003), Ang, et al. (2006), and Eiling (2013). Most measurements of the idiosyncratic risk go to the traditional variance and semivariance. Balzer (1995) and Nawrocko (1999) provide reviews of the risk measurement and suggest the use of semivariance. However, the calculation of semivariance needs benchmark to compute the downside deviation. Different benchmark conceived by different investor would result in different risk measures.

Jan and Wang (2012) propose an objective benchmark, which is named as martingale variance, to obtain a single objective risk measure. They suggest the use of previous return as benchmark instead of mean return to calculate the idiosyncratic risk. The use of previous return is based on the property of martingale. Jan, et al. (2013) apply the new risk measure to examine whether idiosyncratic risk can play an important role in explaining the expected return in Taiwan stock market. They find that idiosyncratic risk has a positive relation to expected returns for stocks with smaller beta portfolio. However, the new measure can't distinguish between the assets whose return rising firstly and then declining, and the assets whose return declining firstly and then rising. In this note, I propose a remedied method, which puts more weight to the recent return's variation and demonstrate that the new weighting risk measure is more close to the investor risk conception.

\section{Weighted Martingale Variance}

The expectation of next period return is today return by the property of martingale. Therefore, Jan and Wang (2012) use previous return as benchmark to measure the martingale variance $(M V A R)$. Specifically, it is calculated as follows: 


$$
\begin{aligned}
\operatorname{MVAR}(R) & =\frac{\sum_{t=1}^{T}\left(R_{t}-R_{t-1}\right)^{2}}{T} \\
& =\frac{2\left\{\left(\sum_{\mathrm{t}=1}^{\mathrm{T}} \mathrm{R}_{\mathrm{t}}^{2}-E(R)^{2}\right)-\left(\sum_{t=1}^{T} R_{t} R_{t-1}-E(R)^{2}\right)\right\}}{T} \\
& =2\left\{\operatorname{VAR}(R)-\operatorname{COV}\left(R_{t}, R_{t-1}\right)\right\}
\end{aligned}
$$

where $R_{t}$ denotes an asset return at time $t, T$ is sample size, and $E(\bullet)$ represents expectation operator. $V A R$ and $C O V$ are conventional variance and covariance operators, respectively. We see that the martingale variance is computed by the variance minus autocorrelation, and is different from the work of Goyal and Santa-Clara (2003) in the second term. Jan and Wang (2012) have provided an example to show the superiority of the martingale variance than the traditional variance. The comparison is shown in Appendix A.

The martingale variance can capture the time series autocorrelation pattern, but can't distinguish the asset whose return are rising, and the return whose return are declining. See also the example presented in Appendix A. The problem can be solved by martingale semivariance ( $M S A V R)$, which can be written as:

$$
\operatorname{MSVAR}(R)=\frac{\sum_{t=1}^{T}\left\{\operatorname{Min}\left(0, R_{t}-R_{t-1}\right)\right\}^{2}}{T}
$$

where $\operatorname{Min}(\bullet, \bullet)$ is minimum operator.

The martingale semivariance can be thought as relative semivariance introduced by Balzer (1995). Nevertheless, the martingale uses past return as the time-varying return benchmark.

Jan, et al. (2013) have shown that the superiority of using martingale semivariance in explaining the expected return in Taiwan stock market. Nevertheless, the martingale semivariance can't distinguish between the assets whose return rising firstly and then declining, and the assets whose return declining firstly and then rising. Take two fictitious assets E and F for example. (Note 1) See Figure 1 as follows.

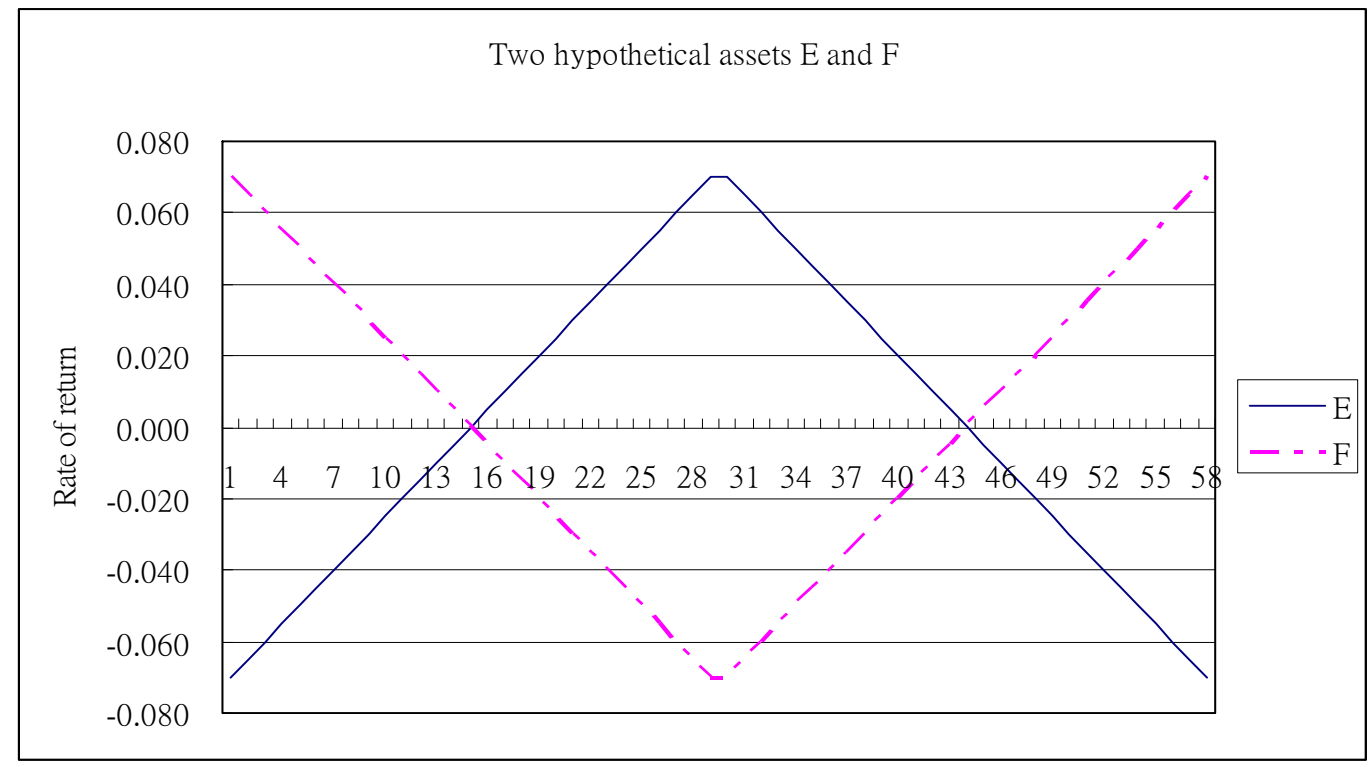

Figure 1. Two hypothetical assets $\mathrm{E}$ and $\mathrm{F}$

We can see that the assets $\mathrm{E}$ and $\mathrm{F}$ have the same measures of variance ,semivariance, martingale variance, and martingale seimivariance. However, most investors would consider the asset $\mathrm{E}$ be riskier than the asset F, because the return of $\mathrm{E}$ is growing and then declining, while the return of $\mathrm{F}$ is declining and then growing. The separation of these two assets risk measure can be reached by the combination of the martingale semivariance and the use of 
weighted average method, which is called weighted martingale semivariance (WMSVAR). That is.

where $w_{t}=t / \sum_{x=1}^{T} x \cdot($ Note 2$)$

$$
\text { WMSVAR } \quad(R)=\sum_{t=1}^{T} w_{t}\left\{\operatorname{Min}\left(0, R_{t}-R_{t-1}\right)\right\}^{2}
$$

The weighted average method can be adjusted to reflect more closely more recent negative return fluctuations. Therefore, more weights are assigned to the most recent data. The calculations of these two assets' weighted martingale semivariance are presented in Figure 2. I set $T=36$ to calculate the risk measure in the total 58 return data. As a result, we have $58-36=22$ moving measures of weighted martingale semivariance. Just as shown in the Figure 2, we can see that the risk measure of $\mathrm{F}$ is larger than those of $\mathrm{E}$ at the outset. However, the risk measures of $\mathrm{F}$ are declining, while those of $\mathrm{E}$ are escalating. The weighted martingale semivariance measures of $\mathrm{E}$ exceed those of $\mathrm{F}$ eventually. When the investors care more to the recent return fluctuation, the weighted method would be closed to the investors risk measure than other measures.

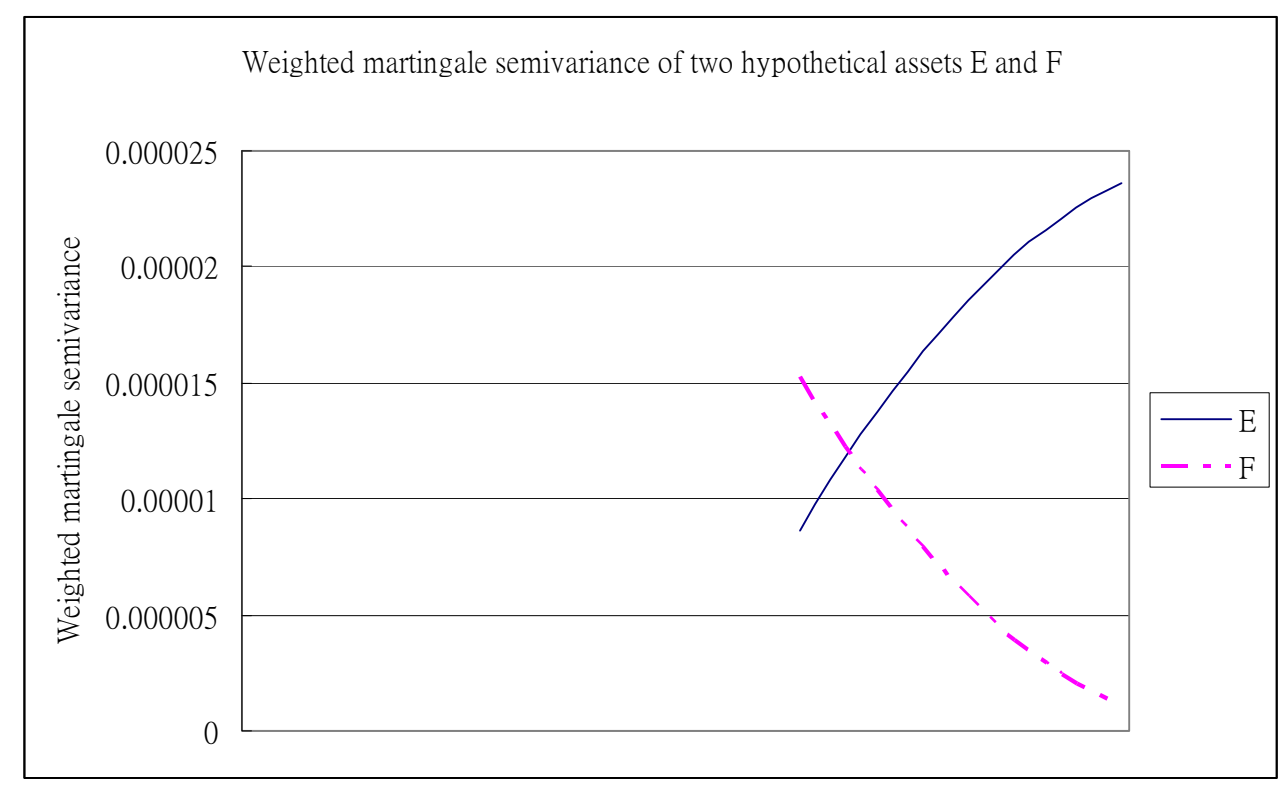

Figure 2. Weighted martingale semivariance of two hypothetical assets $\mathrm{E}$ and $\mathrm{F}$

\section{Conclusion}

Idiosyncratic risk has been proved its role in helping to explain expected asset return. However, we can't get an objective idiosyncratic risk measure without a common benchmark. Jan and Wang (2012) provide an objective risk measure, which is based on the property of martingale. Nevertheless, their risk measure can't distinguish between the assets whose return rising firstly and then declining, and the assets whose return declining firstly and then rising. In this note, I propose a remedied method, which puts more weight to the recent return's variation, and demonstrate that the new weighting risk measure is more close to the investor risk conception. The new risk measure can be applied to improve the performance of portfolio selection and evaluation. I leave these for further research.

\section{Acknowledgements}

I am grateful for comments to two referees and editor. This research is funded by National Chin-Yi University of Technology, NCUT 14-R-MD-023.

\section{References}

Ang, A., Hodrick, R.J., Xing, Y., \& Zhang, Y. (2006). The cross-section of volatility and expected returns. Journal of Finance, 61(1), 259-299. http://dx.doi.org/10.1111/j.1540-6261.2006.00836.x

Balzer, L. (1994). Measuring Investment Risk: A Review. Journal of Investing, 3(3), 47-58. http://dx.doi.org/10.3905/joi.3.3.47

Drew, M. E., Naughton T., \& Veeraraghavan, M. (2004). Is idiosyncratic volatility priced? Evidence from the 
Shanghai Stock Exchange. International Review of Financial Analysis, 13, 349-366. http://dx.doi.org/10.1016/j.irfa.2004.02.027

Drew, M. E., \& Veeraraghavan, M. (2002). Idiosyncratic volatility and security returns: Evidence from the Asian region. International Quarterly Journal of Finance, 2, 1-13.

Eiling E. (2013). Industry-specific human capital, idiosyncratic risk, and the cross-section of expected stock return. Journal of Finance, 68(1), 43-84. http://dx.doi.org/10.1111/j.1540-6261.2012.01794.x

Fu, F. (2009). Idiosyncratic Risk and the Cross-Section of Expected Stock Returns. Journal of Financial Economics, 91(1), 24-37. http://dx.doi.org/10.1016/j.jfineco.2008.02.003

Goyal, A., \& Santa-Clara, P. (2003). Idiosyncratic risk matters! Journal of Finance, 58(3), 975-1008. http://dx.doi.org/10.1111/1540-6261.00555

Jan, Y-C., \& Wang, J.M.C. (2012). A Note on Idiosyncratic Risk Measure. Journal of Money, Investment and Banking, 25, 119-123.

Jan, Y-C., Chiu, S-L., \& Wang, J.M.C. (2013). New Risk Measure and Idiosyncratic Risk in Taiwan Stock Market. International Journal of Financial Research, 4(2), 77-82. http://dx.doi.org/10.5430/ijfr.v4n2p77

Malkiel, B., \& Xu, Y. (1997). Risk and return revisited. Journal of Portfolio Management, 23(3), 9-14. http://dx.doi.org/10.3905/jpm.1997.409608

Nawrocko, D. (1999). A brief history of downside risk measures. Journal of Investing, 8(3), 9-25. http://dx.doi.org/10.3905/joi.1999.319365

Xu, Y., \& Malkiel, B. (2004). Idiosyncratic risk and security returns, AFA 2001 New Orleans Meetings. Retrieved from SSRN:http://ssrn.com/abstract=255303

\section{Notes}

Note 1. These two assets' series return can be found in Appendix B.

Note 2. Other weighted method can be used instead, such as method of exponential smoothing.

\section{Appendix A}

In this Appendix, I follow the work of Jan and Wang (2012) to illustrate the comparison of some risk measures. Firstly, consider two hypothetical assets whose returns (A and B) are shown in Figure A1. We can see that the variance and semivariance of $\mathrm{A}$ and $\mathrm{B}$ are equal. However, most investors would think the asset $\mathrm{B}$ riskier than the asset A, because the return pattern of B is more volatile than A. The more risk of asset A than asset B can be captured by the use of martingale variance. We have seen that the autocorrelation feature has been included in the calculation of martingale variance.

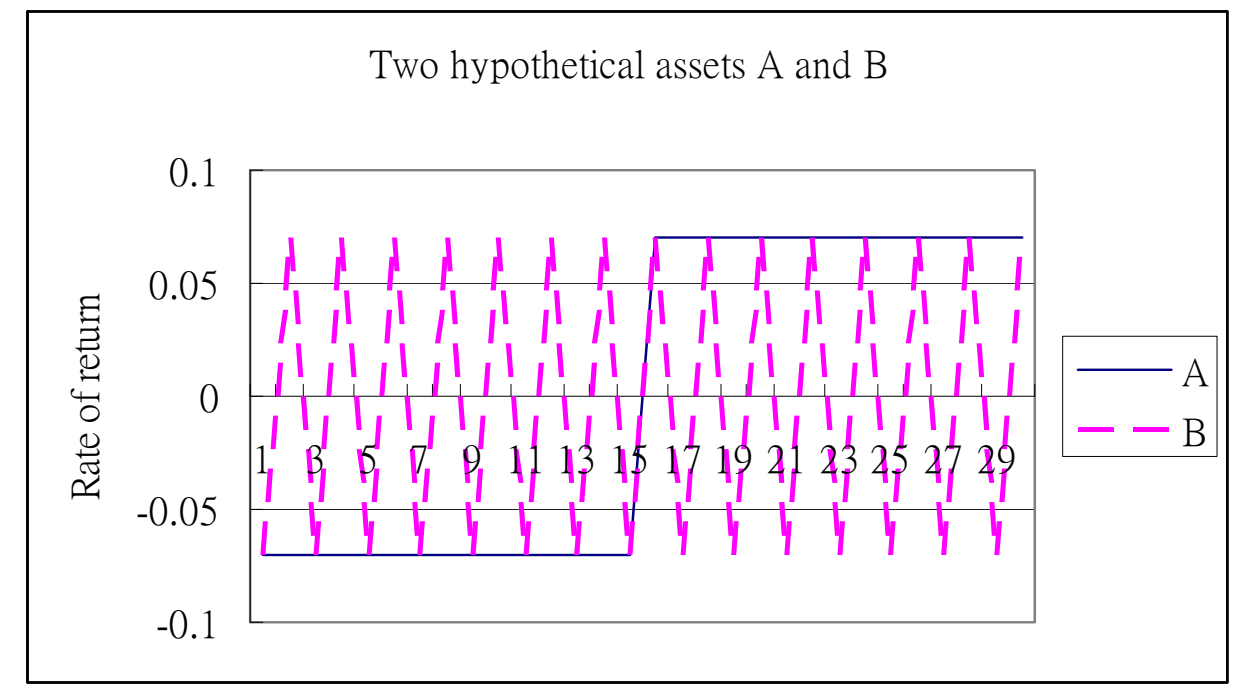

Figure A1. Two hypothetical assets A and B 
However, the martingale variance may not be an adequate risk measure. Take two fictitious assets $\mathrm{C}$ and $\mathrm{D}$ for example. See Figure A2 as follows.

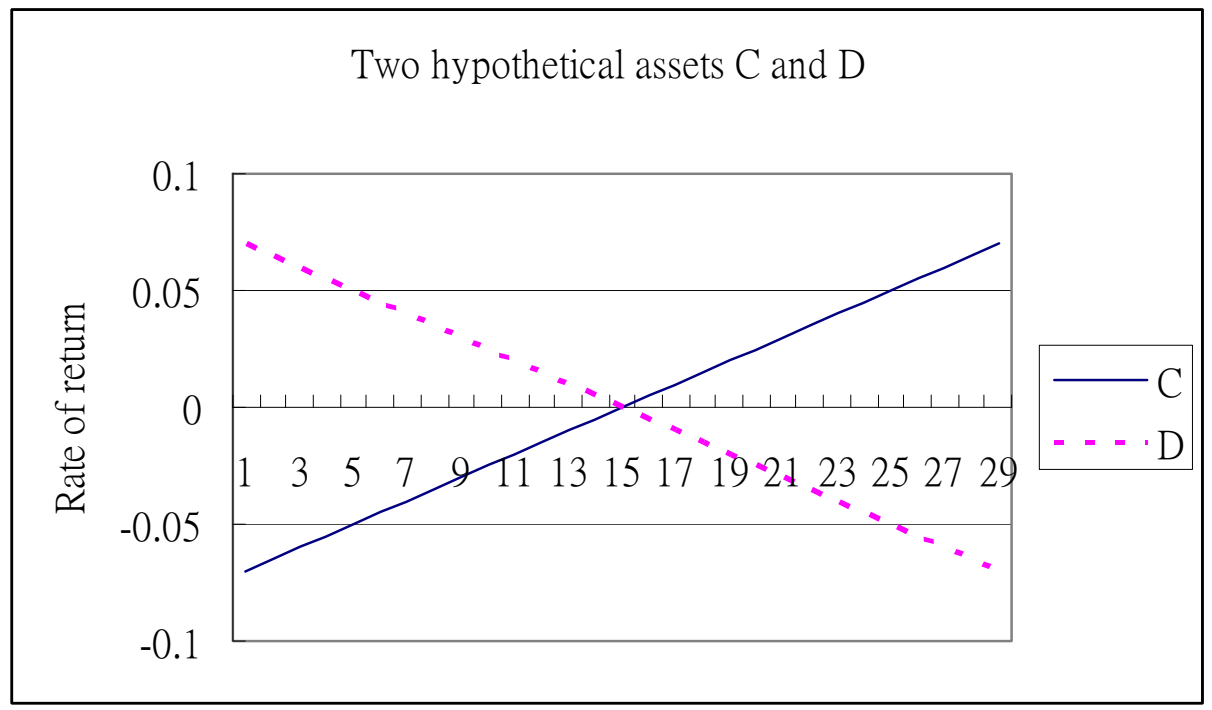

Figure A2. Two hypothetical assets C and D

The return of asset $\mathrm{C}$ is growing, while asset $\mathrm{D}$ is declining. As a result, most investors would consider $\mathrm{D}$ more risky than C. However, the variance, semivariance, and martingale variance of $\mathrm{C}$ are the same as those of $\mathrm{D}$. The problem in the comparison of this two assets $\mathrm{C}$ and $\mathrm{D}$ can be distinguished by the use of martingale semivariance.

\section{Appendix B}

The time-series returns of two hypothetical assets $\mathrm{E}$ and $\mathrm{F}$ are presented as follows.

\begin{tabular}{cccccccccccccccc}
$\mathrm{E}$ & -0.070 & -0.065 & -0.060 & -0.055 & -0.050 & -0.045 & -0.040 & -0.035 & -0.030 & -0.025 & -0.020 & -0.015 & -0.010 & -0.005 & 0 \\
& 0.005 & 0.01 & 0.015 & 0.02 & 0.025 & 0.03 & 0.035 & 0.04 & 0.045 & 0.05 & 0.055 & 0.06 & 0.065 & 0.07 & \\
& 0.07 & 0.065 & 0.06 & 0.055 & 0.05 & 0.045 & 0.04 & 0.035 & 0.03 & 0.025 & 0.02 & 0.015 & 0.01 & 0.005 & 0 \\
& -0.005 & -0.01 & -0.015 & -0.02 & -0.025 & -0.03 & -0.035 & -0.04 & -0.045 & -0.05 & -0.055 & -0.06 & -0.065 & -0.07 & \\
\multirow{2}{*}{$\mathrm{F}$} & 0.070 & 0.065 & 0.060 & 0.055 & 0.050 & 0.045 & 0.040 & 0.035 & 0.030 & 0.025 & 0.020 & 0.015 & 0.010 & 0.005 & 0 \\
& -0.005 & -0.01 & -0.015 & -0.02 & -0.025 & -0.03 & -0.035 & -0.04 & -0.045 & -0.05 & -0.055 & -0.06 & -0.065 & -0.07 & \\
& -0.07 & -0.065 & -0.06 & -0.055 & -0.05 & -0.045 & -0.04 & -0.035 & -0.03 & -0.025 & -0.02 & -0.015 & -0.01 & -0.005 & 0 \\
& 0.005 & 0.01 & 0.015 & 0.02 & 0.025 & 0.03 & 0.035 & 0.04 & 0.045 & 0.05 & 0.055 & 0.06 & 0.065 & 0.07 &
\end{tabular}

